\title{
Experimental Estimation of the Heat Transfer Coefficient of an Unglazed Solar Plate for Unsteady Humid Outdoor Condition
}

\author{
Felix Uba $\mathbb{D}^{1},{ }^{1}$ Eric Osei Essandoh, ${ }^{1}$ Gilbert Ayine Akolgo, ${ }^{1}$ Richard Opoku, ${ }^{2}$ \\ Lawrence Oppong-Kyereh, ${ }^{1}$ and Eric Anokye Gyimah ${ }^{2}$ \\ ${ }^{1}$ Department of Mechanical and Manufacturing Engineering, University of Energy and Natural Resources, Sunyani, Ghana \\ ${ }^{2}$ Department of Mechanical Engineering, Kwame Nkrumah University of Science and Technology, Kumasi, Ghana \\ Correspondence should be addressed to Felix Uba; felix.uba@uenr.edu.gh
}

Received 20 February 2021; Revised 13 August 2021; Accepted 23 August 2021; Published 13 September 2021

Academic Editor: Dimitrios E. Manolakos

Copyright (c) 2021 Felix Uba et al. This is an open access article distributed under the Creative Commons Attribution License, which permits unrestricted use, distribution, and reproduction in any medium, provided the original work is properly cited.

\begin{abstract}
This research presents a study on the heat transfer coefficient for an unglazed solar plate collector in an unsteady humid outdoor environment. The purpose for undertaking this research is to investigate the correlation between the heat transfer coefficient and air speed and also verify whether heat transfer from unglazed solar thermal collectors under outdoor conditions can be experimentally determined using a particular mathematical relationship for different locations. In estimating the heat transfer coefficient for an unglazed solar plate in an unsteady humid outdoor condition, an experiment was held using an outdoor setup that measured temperatures, wind speeds, and solar radiations from 11:00 A.M. to 2:00 P.M. The solar plate collector was placed on a flat bed of height $2.2 \mathrm{~m}$ and a collection area of $0743 \mathrm{~m}^{2}$. An average temperature of $45^{\circ} \mathrm{C}$ was recorded for a mild steel plate collector which was initially exposed to an ambient temperature which ranges from $25^{\circ} \mathrm{C}$ to $32^{\circ} \mathrm{C}$. The interfacial temperature between the plate and an asbestos board ranges from $42^{\circ} \mathrm{C}$ to $52^{\circ} \mathrm{C}$, and that of the asbestos and a plywood is $40^{\circ} \mathrm{C}$ to $46^{\circ} \mathrm{C}$. The specific heat capacity of the mild steel plate and the asbestos board used for the construction of the experimental setup are $25.00 \mathrm{~kJ} / \mathrm{kg}$ and $950.00 \mathrm{~kJ} / \mathrm{kg}$, respectively, while the thermal conductivity of these materials is $0.46 \mathrm{~W} / \mathrm{m} \cdot \mathrm{K}$ and $0.25 \mathrm{~W} / \mathrm{m} \cdot \mathrm{K}$, respectively. The novelty of this work is the use of such a study to generate empirical equations for Ghana and to produce representative equations for determining the heat transfer coefficient for solar plate collectors in unsteady humid outdoor conditions in West Africa. This work is expected to contribute data alongside similar works done for different areas to help propose empirical equations for estimating global and not site-specific heat transfer coefficients.
\end{abstract}

\section{Introduction}

Solar thermal systems such as solar crop dryers, solar thermal cookers, and water and air heaters make use of collectors. Solar collectors are heat exchangers that change solar radiation into the internal heat of transport media in solar thermal systems for practical and useful purposes. However, recent studies including this one have established that unglazed solar thermal systems experience wind-induced convective heat transfer losses due to their external exposures to their immediate surroundings $[1,2]$.

Topmost surface heat loss and heat exchange with adjacent fluids influence the overall thermal performance of solar collector systems. The importance of studying this wind-induced convective heat loss that occurs in unglazed solar thermal systems is that it has a direct effect on the thermal efficiency of solar collector systems [3, 4]. The heat transfer coefficient $h_{w}$ is a parameter influenced by the convection wind speed [5]. This parameter again has useful applications especially for wind-induced solar collectors especially those mounted in natural buoyant environments, hence the need to select appropriate geographical factors $[2,6,7]$.

The value of $h_{w}$ is dependent on the rate of flow of air (wind speed) and the nature of flow which can either be laminar or turbulent indicating the stability or instability of air flow. Laminar flow of air occurs in normal environments where the air movement is considered to be natural and is not influenced by either mechanical devices or obstacles while turbulent flow mostly occurs under artificial conditions where air is moved by mechanical systems like a fan and blower [8]. 
The concept of $h_{w}$ for heat loss estimation is accepted and applied worldwide although consensus has not yet been reached on a standard equation or model for its accurate determination. Because of this, several authors have proposed different empirical equations for specific geographical locations and not on a global scale. This is one of the reasons why the researchers of this work deemed it very necessary to propose an empirical equation for determining the heat transfer coefficient of an unglazed solar collector plate for an unsteady humid outdoor condition in Ghana, a West African country in the sub-Saharan region.

The novelty of this work is the use of an experiment to develop convective heat transfer coefficients for Ghana and to produce representative equations for determining the heat transfer coefficient for solar plate collectors in unsteady humid outdoor conditions in West Africa. This work intends to contribute data alongside similar works done for different areas or regions with the aim of developing empirical equations that can be combined to generate standard equations for determining global and not site-specific heat transfer coefficients in the future.

The volume of work done in this area of research is an indication of how relevant, interesting, and broad this study area is. It is for this reason that this paper has been produced to reveal another area of interest in solar technology experiments. This study specifically estimates the heat transfer coefficient of an unglazed solar plate for unsteady humid outdoor condition; and introduces and as well makes significant contribution in this area of research. This paper comes after numerous previous works including the work done by $[5,9,10]$ which established a functional convective heat transfer model, $h_{w}$, for the interaction between heated surfaces and the ambient air when it comes to the estimation of heat loss by convection.

[5] conducted an experiment with two different layered materials between a top aluminium plate and a bottom thermocole slab (insulator) to determine the heat transfer coefficient as the sun races through the arranged materials. During the experiment, values were taken at a time interval of $1 \mathrm{~s}$ for two years on a $925 \mathrm{~mm} \times 865 \mathrm{~mm} \times 2 \mathrm{~mm}$ aluminium plate. The values were taken during the hours of stable sunshine which happened to be from 12:00 noon to 1:00 P.M. The measurement of these values was done each day from February through March to May. The recorded values were averaged over 10 minutes to reduce the data points, computational time, and cost. A plot of 260 data points of heat transfer coefficients $h_{w}$ and wind speed $V$ gave linear and exponential regressions with an uncertainty value of $7.5 \%$ due to experimental instrumentation errors. The regression coefficient for these equations is 0.78 . In the experiment, asbestos and glass wool slabs were used to retard the flow of the heat received by the aluminium plate to untargeted bodies. The results from the linear regression were then compared with those obtained by $[3,4,10-12]$ and the analytical equation [13]. The comparison of the results turned out that the results obtained by the use of wind tunnel studio setups (controlled environment) designed by [11, 12] and the analytical equation [13] had lower values of the heat transfer coefficient as compared to that of the outside experimental setups employed by [4, 10]. In the cases where the $h_{w}$ values obtained from indoor studios were higher than outdoor setups as presented by [3], this situation can be attributed to the use of artificial devices such as industrial fans which create swirls around the borders of the plates. Swirls create turbulent regions that are very convective with a less developed flow profile. The comparison also satisfies the relation proposed by [9] between the $h_{w}$ and characteristic length, $L$, for the collector. The usual high values obtained for the outdoor setup experiments are as a result of the unsteady and unidirectional nature of the wind which cannot be predicted by indoor studio experiments.

[9] also conducted an experiment to investigate the influence of size on heat transfer coefficient, $h_{w}$, in an outdoor setup. The setup was mounted on a roof top at the Centre for Energy Studies, CES workshop of IIT Delhi. Three setups were used for the experiment; small, medium, and big plates were investigated. The dimensions were $925 \mathrm{~mm}$ $\times 865 \mathrm{~mm} \times 2 \mathrm{~mm}, \quad 500 \mathrm{~mm} \times 865 \mathrm{~mm} \times 2 \mathrm{~mm}$, and 250 $\mathrm{mm} \times 865 \mathrm{~mm} \times 2 \mathrm{~mm}$ for big, medium, and small plates, respectively. The recorded parameters were taken for every second and averaged over a 10-minute interval in a daily duration of one and a half hours so as to reduce the data points, time, and cost of computation. The setup was made of an unglazed dull painted aluminium plate, $3 \mathrm{~mm}$ thick asbestos, $50 \mathrm{~mm}$ thick fibre glass wool slab, and $45 \mathrm{~mm}$ thick thermocole slab fixed at the bottom to prevent heat loss. The readings were taken when the plates' conditions were stable. The linear regressions for the setups were compared separately to establish the dependence of size on the heat transfer coefficient. One of the comparisons done by the study was between the big and medium plates, and another provided a comparison between the big and small plates. The comparison revealed the need for normalisation when the sizes of the plates are not the same; hence, normalisation relations were employed. However, this research also compared the heat transfer coefficient relation (linear regression) with other indoor and outdoor setup relations. Before the comparison, the sizes were normalised using the proposed normalisation relation. The model adopted by this study was compared with $[3,4,11,12]$, and its results were the same as those of [5].

[10] also did an experiment over a roof top to estimate the heat transfer coefficient. The studio was placed outside with layered construction materials held together in a wooden case. The first layer is a $2 \mathrm{~mm}$ aluminium sheet with a $1.81 \mathrm{~m} \times 0.89 \mathrm{~m}$ area painted matt black to increase its absorptivity to 0.97 with an emissivity of 0.90 . In the experiment, a heating element was provided beneath the aluminium plate with a thickness of $2 \mathrm{~mm}$. The bottom was enclosed with an aluminium foil to reflect heat toward the aluminium plate. The whole layer was then covered below with a $100 \mathrm{~mm}$ thick polystyrene insulator. The linear regression correlation between the $h_{w}$ and $V$ developed was compared with a convection heat loss algorithm created by Jurges documented by [11] and also compared with the works of [14] and with Test et al.'s experiment [4]. The result showed a great relation especially with the values 
obtained by [4]. The lower values of the other two models $[11,14]$ are as a result of the stable nature of the prevailing surrounding conditions. This can also be attributed to the presence of developed flow profiles.

This research has established the need to develop a heat transfer coefficient empirical model for each and every geographical area since both analytical and numerical models launched by several authors could not eliminate or erode the infringements in the estimation of the heat transfer coefficient. This deficiency is investigated by this study, and the authors of this research really recommend the comprehensive investigation of this phenomenon by future studies. It has also been established by this study that a seemingly similar equation was used by previous works to estimate the heat transfer coefficient in outdoor conditions even though outdoor heat transfer coefficients are site-specific. For this reason, this study is proposing the use of different appropriate models for determining heat transfer coefficients for Ghana specifically Sunyani as the performance of thermal systems depends on local conditions such as solar irradiation, rainfall, and localized wind-induced convection.

\section{Materials and Methods}

This section talks about the experimental setup, validated data, and the development of a model as well as comparing the developed model to previous works.

2.1. Heat Transfer Models. There are several linear regressions introduced in Introduction which are used as a benchmark for validating data and comparing the model produced by this research. The models are represented in Table 1 and the environment in which they were performed. The differences in these models are due to the prevailing experimental conditions. These models are normalised to make it comparable to the new model produced by this study as stated in Introduction.

2.2. Method. This section describes the experimental setup used to evaluate the heat transfer coefficient for a horizontal flat plate solar collector under environmental conditions in the University of Energy and Natural Resources, Sunyani campus. The experimental setup involves three major materials, namely, mild steel plate, asbestos board, and plywood. The arrangement is shown in Figure 1. The mild steel plate is of a thickness of $0.1 \mathrm{~cm}$ whereas the asbestos board is produced to a thickness of $2 \mathrm{~cm}$. The plywood $(100 \mathrm{~cm}$ thick) was used to insulate the whole setup $(61 \mathrm{~cm} \times 122 \mathrm{~cm})$ to prevent heat loss into the environment through the sides and the base of the experimental setup. The mild steel plate at the top is meant to allow heat transfer through conduction and convection only. The interfacial connection between the plate and the asbestos and also between the asbestos and plywood was made air tight by creating the asbestos board with a liquid-phase asbestos paste, thus ensuring the necessary flow of the asbestos paste in filling the unfilled cavities in the layered board used for the experiment. The use of the liquid-phase asbestos paste is intended to eliminate the interfacial resistance to heat transfer due to air gaps at the
TABLE 1: Models developed by previous works.

\begin{tabular}{|c|c|c|c|}
\hline $\begin{array}{l}\text { S/ } \\
\mathrm{N}\end{array}$ & Model & Reference & $\begin{array}{l}\text { Setup/ } \\
\text { studio }\end{array}$ \\
\hline 1 & $h_{w}=5.7+3.8 V_{w} \quad V_{w} \leq 5 \mathrm{~m} / \mathrm{s}$ & [11] & Indoor \\
\hline 2 & $h_{w}=2.8+3 V_{w} \quad V_{w} \leq 5 \mathrm{~m} / \mathrm{s}$ & {$[12]$} & Indoor \\
\hline 3 & $h_{w}=8.55+2.56 V_{w} \quad V_{w} \leq 5 \mathrm{~m} / \mathrm{s}$ & {$[4]$} & Outdoor \\
\hline 4 & $h_{w}=10.03+4.687 V_{w} \quad V_{w} \leq 5 \mathrm{~m} / \mathrm{s}$ & [3] & Indoor \\
\hline 5 & $h_{w}=6.5+3.3 V_{w} \quad V_{w} \leq 6 \mathrm{~m} / \mathrm{s}$ & {$[10]$} & Outdoor \\
\hline
\end{tabular}

two interfacial planes (mild steel and asbestos and asbestos and plywood).

The experiment was performed from March to August, 2020, in Sunyani, the regional capital of the Bono Region of Ghana. The period for this research begins from the hottest month and spans the most raining months (April-July) established in Ghana to August thus exposing this experiment to a considerable amount of humidity. To avoid the possibility of introducing errors in the findings of this experiment as a result of rains, it was only held on days when there was no rain and the sunshine was relatively high. The outside experiment was performed from 11:00 A.M. to 2:00 P.M. each day when the solar radiation was stable and at its maximum or peak value in Ghana. The mild steel plate was held horizontally on a $7 \mathrm{ft}$ (about $2.2 \mathrm{~m}$ ) high horizontal board platform in an open space. The mild steel plate in the experimental setup was illuminated with solar radiation. The solar energy is intercepted by the mild steel plate which gets hot and consequently transfers its heat into the asbestos through conduction at a very low rate. In this experiment, it is assumed that there is no heat generation and the plywood thermally insulates the setup from heat loss and acts as a boundary for the experiment at both the sides and the bottom. The metal plate acts as a special heat exchanger, with a little of its sensible heat conducted into the asbestos material and the rest of the heat transferred to the environment by convection.

To estimate the amount of heat transferred into the convective atmosphere, an energy balance is applied across the system (Figure 1). Figure 1(a) is the schematic diagram of the experimental setup while Figure 1(b) shows the plate geometry whose heat transfer coefficient is to be determined under outdoor conditions. Figure 1(c) depicts the pictorial view of the setup. The temperatures are taken between the interfacial boundaries (i.e., mild steel metal and asbestos and asbestos and plywood). They are denoted by $\mathbf{T}_{\text {asb, } \mathbf{i}}$ and $\mathbf{T}_{\text {asb,f }}$, respectively. These quantities were measured for every minute spanning a daily period of 3 hours for four months under natural outdoor wind speeds. The specific heat capacity properties of the mild steel plate and asbestos board used for the construction of the experimental setup are $25.00 \mathrm{~kJ} / \mathrm{kg}$ and $950.00 \mathrm{~kJ} / \mathrm{kg}$, respectively, while the thermal conductivity of the same materials is $0.46 \mathrm{~W} / \mathrm{m} \cdot \mathrm{K}$ and $0.25 \mathrm{~W} / \mathrm{m} \cdot \mathrm{K}$, respectively.

2.3. Energy Balance for Estimating the Heat Transfer Coefficient. Using the experimental setup shown in 


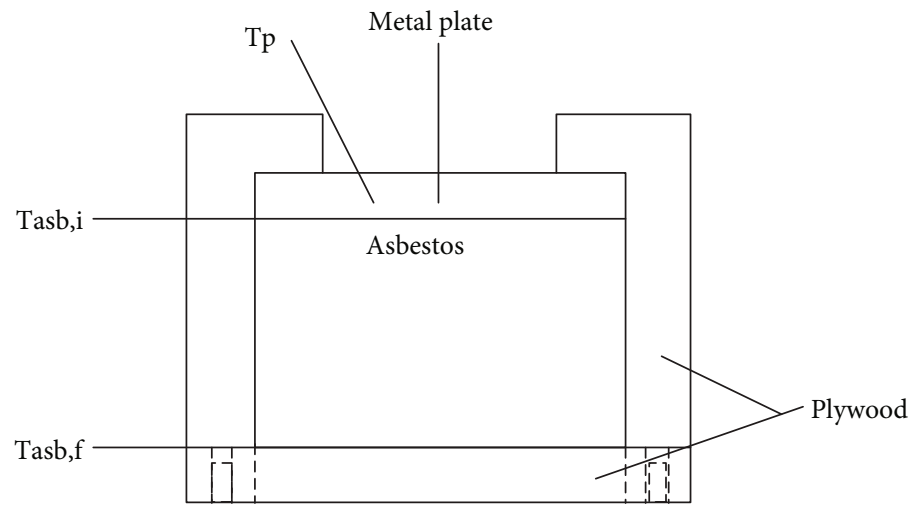

(a)

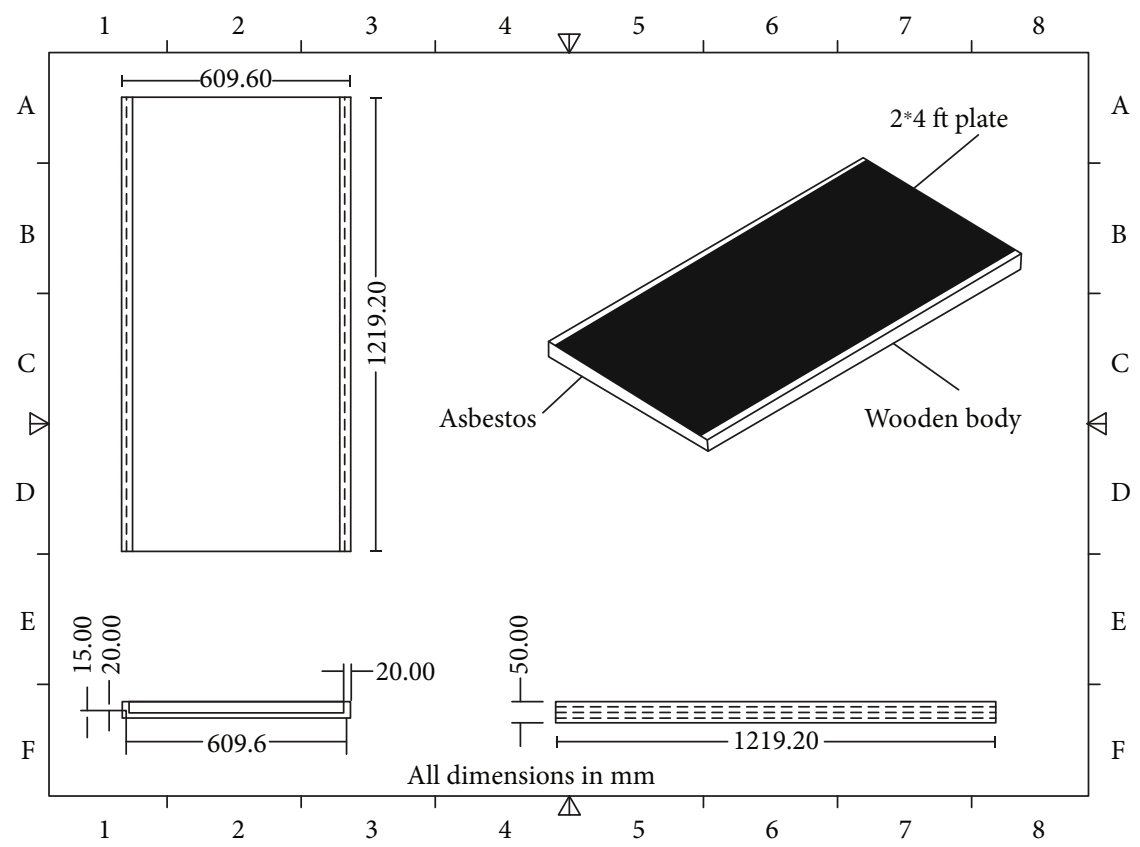

(b)

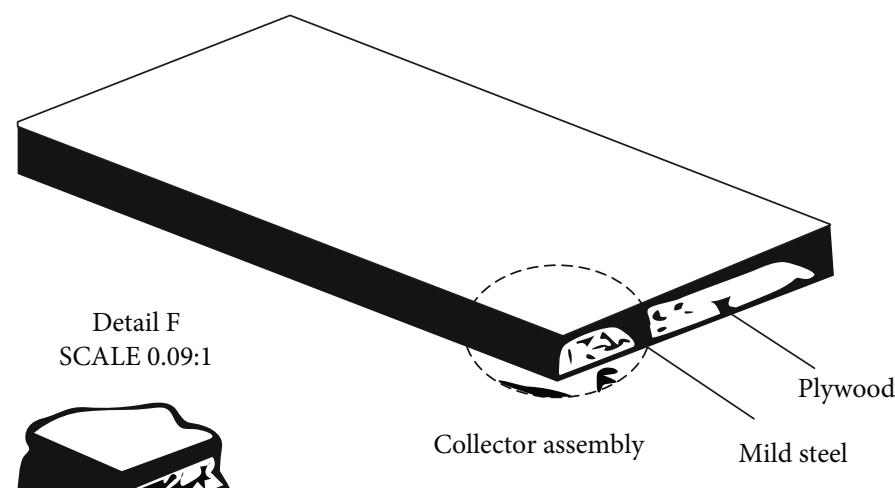

(c)

Figure 1: Solar Flat Plate construction showing its various components: (a) sectional view, (b) orthogonal view, and (c) pictorial view

Figure 1, the amount of energy absorbed from the heat source by the plate is expressed in Equation (1). The heat released by the sun is the algebraic sum of the heat absorbed by the plate, heat radiated from the plate surface to the sky, heat conducted by the asbestos material, and the heat transferred from the plate to the environment through convection:

$$
\dot{Q}_{\text {in }}^{\prime}=\dot{Q}_{\text {condlos }}^{\prime}+\dot{Q}_{\text {radlos }}^{\prime}+\dot{Q}_{\text {abplate }}^{\prime}+\dot{Q}_{\text {convlos }}^{\prime}
$$


where $\dot{Q}_{i n}^{\prime}$ is the rate of heat absorbed by the metal plate, $\dot{Q}_{\text {condlos }}^{\prime}$ is the rate of heat conducted by asbestos, $\dot{Q}_{\text {convlos }}^{\prime}$ is the rate of heat transferred by the plate through convection, $\dot{Q}_{\text {radlos }}^{\prime}$ is the rate of heat radiated by the metal plate, and $\dot{Q}_{\text {abplate }}^{\prime}$ is the rate of sensible heat absorbed to raise the temperature of the metal plate; all these quantities are measured per unit area.

The incident thermal energy absorbed by the mild steel plate is given by

$$
\dot{Q}_{\text {in }}^{\prime}=\alpha_{\mathrm{p}} I
$$

where $\alpha_{\mathrm{p}}$ is the volumetric property of the mild steel plate (i.e., absorptivity, a dimensionless quantity) and $I$ is the radiation intensity and is given in $\mathrm{W} / \mathrm{m}^{2}$.

The amount of heat conducted from the mild steel plate to the asbestos board is given by

$$
\begin{gathered}
\dot{\mathrm{Q}}_{\text {condloss }}^{\prime}=m_{\mathrm{asb}} \mathcal{c}_{\mathrm{pasb}} \frac{d T_{\mathrm{asb}}}{d t}+\frac{k_{\mathrm{asb}}\left(T_{\mathrm{asb}, \mathrm{i}}-T_{\mathrm{asb}, \mathrm{f}}\right)}{(d x)}, \\
d T_{\mathrm{asb}}=T_{\mathrm{asb}, \mathrm{i}}-T_{\mathrm{asb}, \mathrm{f}}, \\
T_{\mathrm{asb}, \mathrm{i}}=T_{\mathrm{p}}, \\
(d t)=\text { time interval, }
\end{gathered}
$$

where the terms on the right-hand side of Equation (3) stand for heat stored and conducted by the asbestos, respectively.

Considering that the metal plate is enveloped by a large surface (i.e., the sky), the radiative heat transfer is given as

$$
\dot{Q}_{\text {radlos }}^{\prime}=\sigma \varepsilon_{\mathrm{p}}\left(T_{\mathrm{p}}^{4}-T_{\text {sky }}^{4}\right),
$$

where $T_{\mathrm{p}}$ and $T_{\text {sky }}$ represent the temperature of the plate and sky, respectively. Since the temperature of the sky cannot be directly measured by the study, it is estimated using

$$
T_{\text {sky }}=0.05552 T_{\mathrm{amb}}^{1.5} \text {. }
$$

The amount of sensible heat absorbed by the mild steel plate to raise its temperature is given by

$$
\dot{Q}_{\text {abplate }}^{\prime}=m_{\mathrm{p}} c_{\mathrm{p}} \frac{d T_{\mathrm{p}}}{d t}+\frac{k_{\mathrm{p}}\left(T_{\mathrm{p}}-T_{\mathrm{asb}, \mathrm{i}}\right)}{(d x)} .
$$

The convective heat transfer into the atmosphere can be estimated using

$$
\dot{Q}_{\text {convlos }}^{\prime}=h_{w}\left(T_{\mathrm{p}}-T_{\mathrm{amb}}\right) .
$$

When Equations (2) through (3) to (7) are combined to yield Equation (8), $h_{w}$ can then be derived.

$$
h_{w}=\frac{\left[\alpha_{\mathrm{p}} I-(A+B+C)\right]}{\left(T_{\mathrm{p}}-T_{\mathrm{amb}}\right)} .
$$

The relations for the constants in Equation (8) are given in

$$
\begin{gathered}
\mathbf{A}=\mathbf{m}_{\mathrm{asb}} \mathbf{c}_{\mathbf{p}, \mathbf{a s b}} \frac{\mathbf{d} \mathbf{T}_{\text {asb }}}{\mathbf{d t}}+\frac{\mathbf{k}_{\mathrm{asb}}\left(\mathbf{T}_{\mathrm{asb}, \mathbf{i}}-\mathbf{T}_{\mathrm{abb}, \mathbf{f}}\right)}{(\mathbf{t})}, \\
B=\sigma \varepsilon_{\mathrm{p}}\left(T_{\mathrm{p}}^{4}-T_{\mathrm{sky}}^{4}\right) \\
C=m_{\mathrm{p}} c_{\mathrm{p}} \frac{d T_{\mathrm{p}}}{d t}+\frac{k_{\mathrm{p}}\left(T_{\mathrm{p}}-T_{\mathrm{asb}, \mathrm{i}}\right)}{(d x)}
\end{gathered}
$$

2.4. Uncertainty Analysis. Estimation of uncertainty from the measurement of $h_{w}$ values during the experiment can be calculated from Equations (10) through (11) to (12):

$$
\begin{gathered}
h_{w}=\left(\frac{\dot{Q}_{\text {in }}^{\prime}-\dot{Q}_{\text {condlos }}^{\prime}+\dot{Q}_{\text {radlos }}^{\prime}+\dot{Q}_{\text {abplate }}^{\prime}}{\left(T_{\mathrm{p}}-T_{\text {amb }}\right)}\right), \\
W_{h_{w}}=h_{w}\left\{\left(\frac{\partial h_{w}}{\partial \dot{Q}_{\text {in }}^{\prime}} \frac{w_{\dot{Q}_{\text {in }}}}{h_{w}}\right)^{2}+\left(\frac{\partial h_{w}}{\partial \dot{Q}_{\text {abplate }}^{\prime}} \frac{w_{\dot{Q}_{\text {abphate }}}}{h_{w}}\right)^{2}\right. \\
+\left(\frac{\partial h_{w}}{\partial \dot{Q}_{\text {condlos }}^{\prime}} \frac{w_{\dot{Q}_{\text {condlos }}}}{h_{w}}\right)^{2}+\left(\frac{\partial h_{w}}{\partial \dot{Q}_{\text {radlos }}^{\prime}} \frac{w_{\dot{Q}_{\text {radlos }}}}{h_{w}}\right)^{2} \\
\left.+\left(\frac{\partial h_{w}}{\partial T_{\mathrm{p}}} \frac{w_{T_{\mathrm{p}}}}{h_{w}}\right)^{2}+\left(\frac{\partial h_{w}}{\partial T_{\mathrm{amb}}} \frac{w_{T_{\text {amb }}}}{h_{w}}\right)^{2}\right\}^{1 / 2}, \\
\frac{\partial h_{w}}{\partial \dot{Q}_{\mathrm{in}}^{\prime}}=-\frac{\partial h_{w}}{\partial \dot{Q}_{\mathrm{abplate}}^{\prime}}=\frac{\partial h_{w}}{\partial \dot{Q}_{\text {condlos }}^{\prime}}=\frac{\partial h_{w}}{\partial \dot{Q}_{\text {radlos }}^{\prime}}=\frac{1}{\left(T_{\mathrm{p}}-T_{\mathrm{amb}}\right)}, \\
\frac{\partial h_{w}}{\partial T_{\mathrm{p}}}=-\frac{\alpha_{\mathrm{p}} I-(A+B+C)}{\left(T_{\mathrm{p}}-T_{\mathrm{amb}}\right)^{2}}, \\
\frac{\partial h_{w}}{\partial T_{\mathrm{amb}}}=\frac{\alpha_{\mathrm{p}} I-(A+B+C)}{\left(T_{\mathrm{p}}-T_{\mathrm{amb}}\right)^{2}},
\end{gathered}
$$

where $w_{\dot{Q}_{\text {in }}}, w_{\dot{Q}_{\text {abpplate }}}, w_{\dot{Q}_{\text {condlos }}}, w_{\dot{Q}_{\text {radlos }}}, w_{T_{\mathrm{p}}}, w_{T_{a}}$ are errors in $\dot{Q}_{\mathrm{in}}^{\prime}$ $\dot{Q}_{\text {abplate }}^{\prime} \dot{Q}_{\text {condlos }}^{\prime} \dot{Q}_{\text {radlos }}^{\prime} T_{\mathrm{p}}$, and $T_{a}$, respectively, according to the order in which these notations are presented.

The error in the estimation of $w_{\dot{Q}_{\text {in }}}$ emanates from the measurement of two variables (absorptivity $\alpha_{\mathrm{p}}$ and the irradiation $I$ of the plate) in which only the measurement of $I$ is found to be varying ( $\alpha_{\mathrm{p}}$ is constant) in this case. It can be estimated from

$$
\begin{gathered}
w_{\dot{Q}_{\text {in }}}=\dot{Q}_{\text {in }}^{\prime}\left\{\left(\frac{\partial \dot{Q}_{\text {in }}{ }^{\prime \prime}}{\partial I} \frac{w_{I}}{\dot{Q}_{\text {in }}{ }^{\prime \prime}}\right)^{2}\right\}^{1 / 2}, \\
w_{\dot{Q}_{\text {in }}}=\dot{Q}_{\text {in }}^{\prime}\left(\frac{w_{I}}{I}\right),
\end{gathered}
$$

where $w_{I}$ represents the accuracy in measuring solar radiation. Its value is taken to be equal to $2.5 \%$ of the total solar irradiation $I$ as suggested by [5]. 
Similarly, the errors in heat absorbed and conducted in the mild steel plate are obtained from

$$
\begin{aligned}
& w_{\dot{Q}_{\text {abplate }}}=\dot{Q}_{\text {abplate }}^{\prime}\left\{\left(\frac{w_{\text {thick }}}{\text { thick }}\right)^{2}+\left(\frac{w_{T_{\mathrm{p} 2}}}{T_{\mathrm{p} 2}-T_{\mathrm{p} 1}}\right)^{2}\right. \\
& \left.+\left(\frac{-w_{T_{\mathrm{p} 1}}}{T_{\mathrm{p} 2}-T_{\mathrm{p} 1}}\right)^{2}+\left(\frac{w_{d t}}{d t}\right)^{2}\right\}^{1 / 2} \\
& w_{\dot{Q}_{\text {condlos }}}=\dot{Q}_{\text {condloss }}^{\prime}\left\{\left(\frac{w_{k_{\mathrm{asb}}}}{k_{\mathrm{asb}}}\right)^{2}+\left(\frac{w_{T_{\mathrm{asb}, \mathrm{i}}}}{T_{\mathrm{asb}, \mathrm{i}}-T_{\mathrm{asb}, \mathrm{f}}}\right)^{2}\right. \\
& +\left(\frac{-w_{T_{\text {asb, }}}}{T_{\text {asb }, \mathrm{i}}-T_{\text {asb }, \mathrm{f}}}\right)^{2}+\left(\frac{w_{\text {thick }_{\text {asb }}}}{\text { thick }_{\text {asb }}}\right)^{2}+\left(\frac{w_{\left(\dot{Q}_{s}\right)_{\text {asb }}^{\prime}}}{\dot{Q}_{\text {condloss }}^{\prime}}\right)^{2} \\
& \left.+\left(\frac{w_{d t}}{d t}\right)^{2}\right\}^{1 / 2}
\end{aligned}
$$

where $w_{\left(\dot{Q}_{s}\right)_{\text {asb }}^{\prime}}$ represents uncertainties/errors in the measurement of the heat energy stored in the asbestos per unit time and area.

The error involved in the radiation is also expressed in

$$
\begin{aligned}
w_{\dot{Q}_{\text {radlos }}}= & \dot{Q}_{\text {radlos }}^{\prime}\left\{\left(\frac{w_{T_{\mathrm{p}}} \cdot 4 T_{\mathrm{p}}^{3}}{\left[T_{\mathrm{p}}^{4}-\left(0.0552^{4} T_{a}^{6}\right)\right]}\right)^{2}\right. \\
& \left.+\left(\frac{-w_{T_{a}} \cdot\left(0.0552^{4} \cdot 6 T_{a}^{5}\right)}{\left[T_{\mathrm{p}}^{4}-\left(0.0552^{4} T_{a}^{6}\right)\right]}\right)^{2}\right\}^{1 / 2},
\end{aligned}
$$

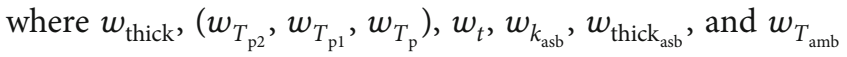
represent the errors in measuring metal plate thickness, metal plate temperatures, time interval, asbestos conduction coefficient, asbestos thickness, and ambient temperature (according to the order of the measurement errors given above).

The errors found in the experiment are listed in Table 2.

\section{Results and Discussion}

The results obtained from the experiment conducted by this study are discussed here. The discussion was done based on both pictorial and numerical results which portrayed the trends observed in the experiment.

3.1. Weather and Experimental Conditions. The period used for the experiment spanned March to August, and in Ghana, it is the period when the rain begins to fall with consistency (the month of March) and when the frequency of the annual rainfall begins to dwindle for most of the year (the month of August) as established by the climatic data of Ghana (courtesy of Ghana Meteorological Authority). The months of April through May to July were the most humid months of the period used for this study; thus, the weather condition for this experiment can be described as rainy and humid.
Since the experiment was done outdoor, the weather conditions were the same for the experiment. However, in terms of the physical conditions created by the experimental setup, the fluid flow condition for the experiment can be said to be transition flow due to the relatively low and the large intermittent air speeds created by the surrounding trees at the site and the obstruction caused by the experimental setup itself.

3.2. Thermal Analysis and Heat Transfer Coefficient. The heat transfer terms were calculated using the average values measured in every 10 minutes. Figure 2 shows that the radiation received by the mild steel plate is almost stable. The slight variation in the radiation intensity can be attributed to the attenuation of the solar radiation. To reduce this effect, the experiment was planned and held during a period when the sun peaks in most parts of Ghana. The sun peak hours in which this experiment was conducted start from 11:00 A.M. and end at 2:00 P.M. The temperature variations for the mild steel plate/asbestos and asbestos/plywood interfaces are shown in Figure 3.

From Figure 3(a), the mild steel plate temperature and the interfacial plate/asbestos temperature curves coincide. These temperature-time curves are seen as the first curve on top of Figure 3(a). This phenomenon can be explained by the fact that the plate is very thin $(0.1 \mathrm{~cm})$ and has a very good conductive coefficient which does not create room for any heat storage.

It is assumed that the particles of the mild steel plate transfer its thermal energy to adjacent molecules as quickly as possible without any initial storage of heat before permitting transfer of heat from the molecules closer to the heat source to those farther away from the source of heat and other bodies. The second temperature curve from the top as obtained from the interfacial asbestos/plywood shows that there is resistance to the flow of heat through the asbestos board. This resistance to heat transfer offered by the asbestos creates difference in temperature or heat gradients. The fall in the initial values of the mild steel plate and the two interfacial temperatures is due to sensible heating of the asbestos board. The temperature curves are all seen to rise with time because the heating of the asbestos board by the sun was not obstructed in the experiment or the setup was allowed to receive incremental heat for the whole span of the experiment.

The mild steel plate surface was treated with a matt black paint to increase its absorptivity. This treatment positively affected the amount of heat absorbed by the plate as it absorbed more heat from the incident radiation.

The last or the third curve from the top (also in Figure 3(a)) represents the ambient temperature which was found to be the lowest recorded temperature in the experiment.

Figure 3(b) shows the heat transfer mechanisms, i.e., the heat absorbed by plate, the heat conducted, and the heat radiated as discussed in Method.

The uppermost curve represents the incident solar radiation on the plate and is followed by the heat absorbed by the plate. The difference in the two curves is due to the nature of the surface. A reflective or mirror surface reflects 
TABLE 2: Instrumentation errors.

\begin{tabular}{lcc}
\hline Quantity & Symbol & Error \\
\hline Metal plate thickness & $w_{\text {thick }}$ & $1 \mathrm{~mm}=0.001 \mathrm{~m}$ \\
Metal plate temperatures & $\left(w_{T_{p 2}}, w_{T_{p 1}}, w_{T_{p}}\right)$, & $0.1^{\circ} \mathrm{C}$ \\
Time & $w_{\tau}$ & $1 \mathrm{~s}$ \\
Insulator conduction coefficient & $w_{k_{\text {ins }}}$ & $0.002 \mathrm{~W} / \mathrm{m} \cdot \mathrm{K}$ \\
Insulator thickness & $w_{\text {thick }}$ & $1 \mathrm{~mm}=0.001 \mathrm{~m}$ \\
Ambient temperature & $w_{T_{a}}$ & $0.1^{\circ} \mathrm{C}$ \\
\hline
\end{tabular}

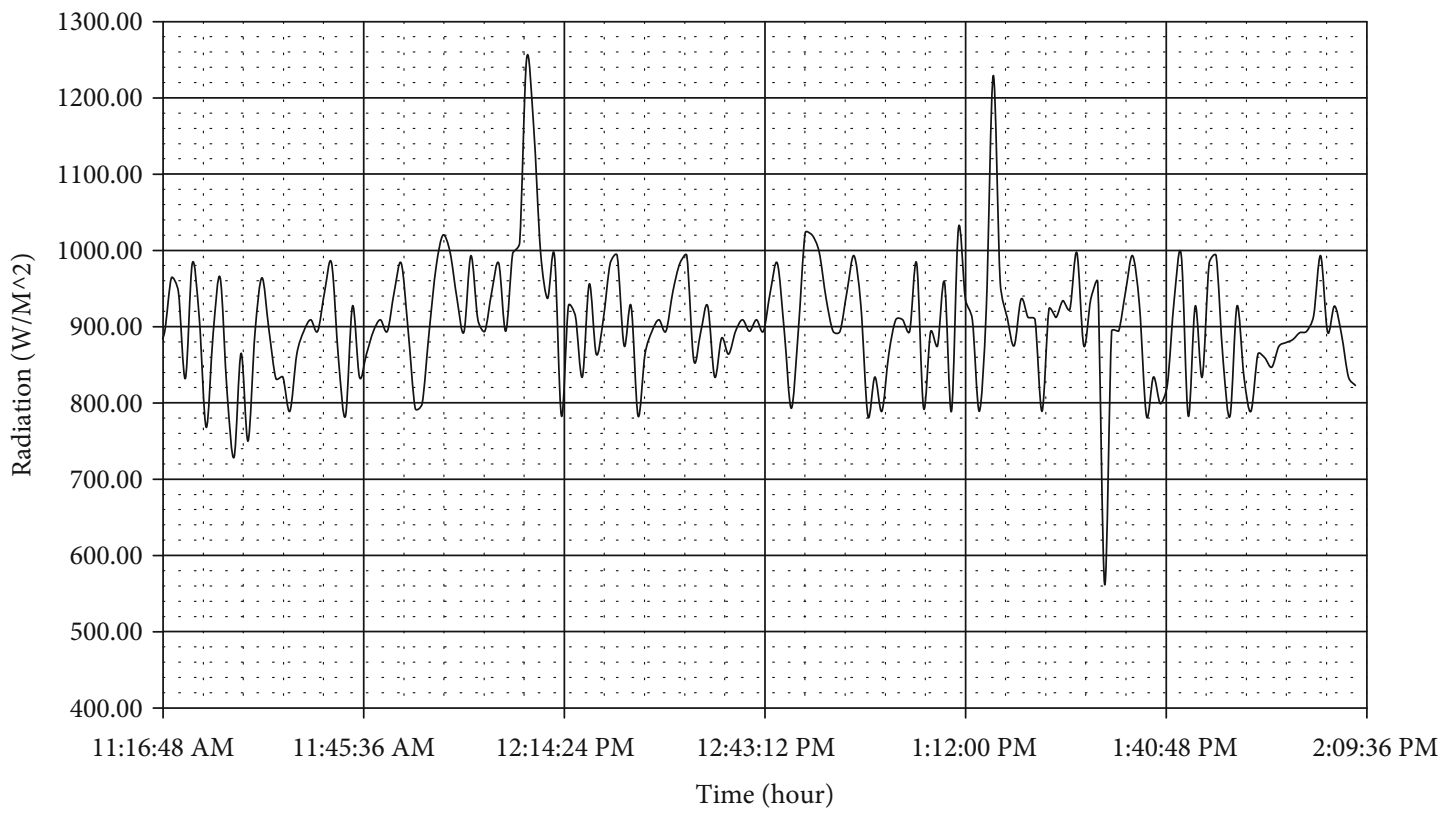

FIgURE 2: Solar radiation on a plate (source: Authors, 2021).

a large amount of the heat radiation while a matt black or dull surface absorbs more. The mild steel plate with a matt black surface had an absorptivity of 0.9 making it to approach a black body surface, thus absorbing a relatively maximum amount of the incident radiation. Another notable thing is the flow; i.e., there is no time lag between the two. The heat released to the asbestos by the mild steel plate is made possible by conduction. This thermal energy is transferred to the asbestos board as a sensible heat by increasing its temperature. The third curve shows the heat flux through the asbestos board. The heat flux curve is seen falling suddenly at the beginning, and this is due to the sensible heating that takes place before the heat flux through the asbestos board begins. Immediately after the sensible heating of the asbestos board, its temperature starts to rise and this can be seen in Figure 3(b). The last two curves show the heat flux radiated by plate and the heat that caused the sensible heating of the mild steel plate, respectively. The small values of these heat transfers are as a result of the surface treatment and the thickness of the mild steel plate. The thermal conductivity of asbestos, an insulator, is obviously lower than that of a conductor (mild steel plate), hence the great difference in the heat flux through the plate and the asbestos.

The heat transfer coefficients were also estimated for every minute from Equation (8). The heat transfer coefficients are dependent on the air speed. Higher air speed results in higher heat transfer coefficient values whereas lower values of air speed resulted in smaller coefficients.

The erratic changes in the air speeds affected the readings obtained, and because of this, the heat transfer coefficient values were estimated with these effects in mind. Astronomical temperature values above $60^{\circ} \mathrm{C}$ were occasionally attained by the mild steel plate as a result of the winds created by trees around the study area. The location is a forest zone with intermittent wind speeds that can go as high as $7 \mathrm{~m} / \mathrm{s}$. From $[4,11,12]$, the coefficients range from 0 to $30 \mathrm{~W} / \mathrm{m}^{2} \cdot \mathrm{K}$, and it provided some basis for the evaluation of the heat transfer coefficient obtained by this study. During the evaluation, values above $40 \mathrm{~W} / \mathrm{m}^{2} \cdot \mathrm{K}$ were excluded from the data and the rest were used for the analysis. $2 \%$ of the values from 201 data points were masked out leaving only 197 data points which means that the values excluded did 


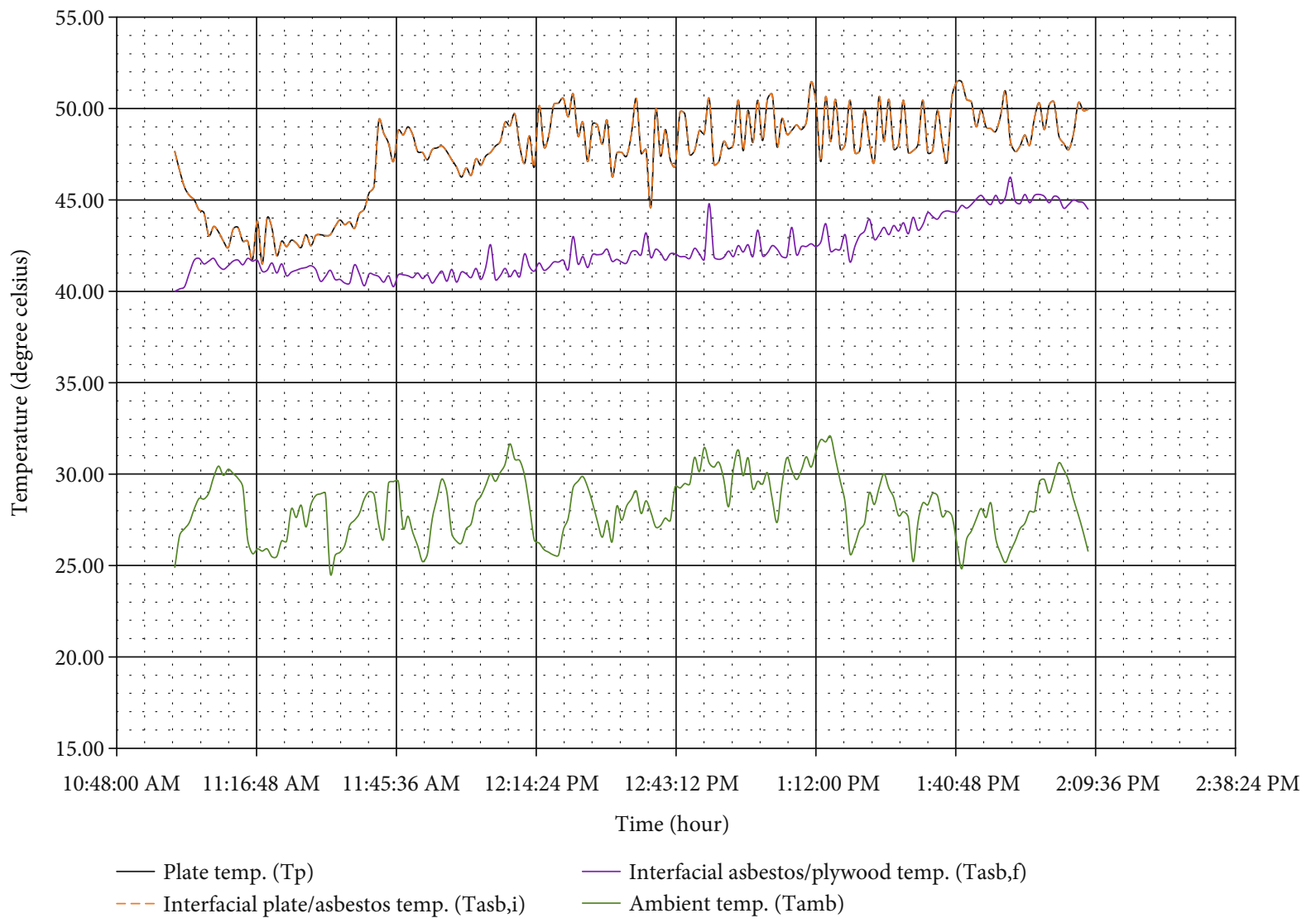

(a)

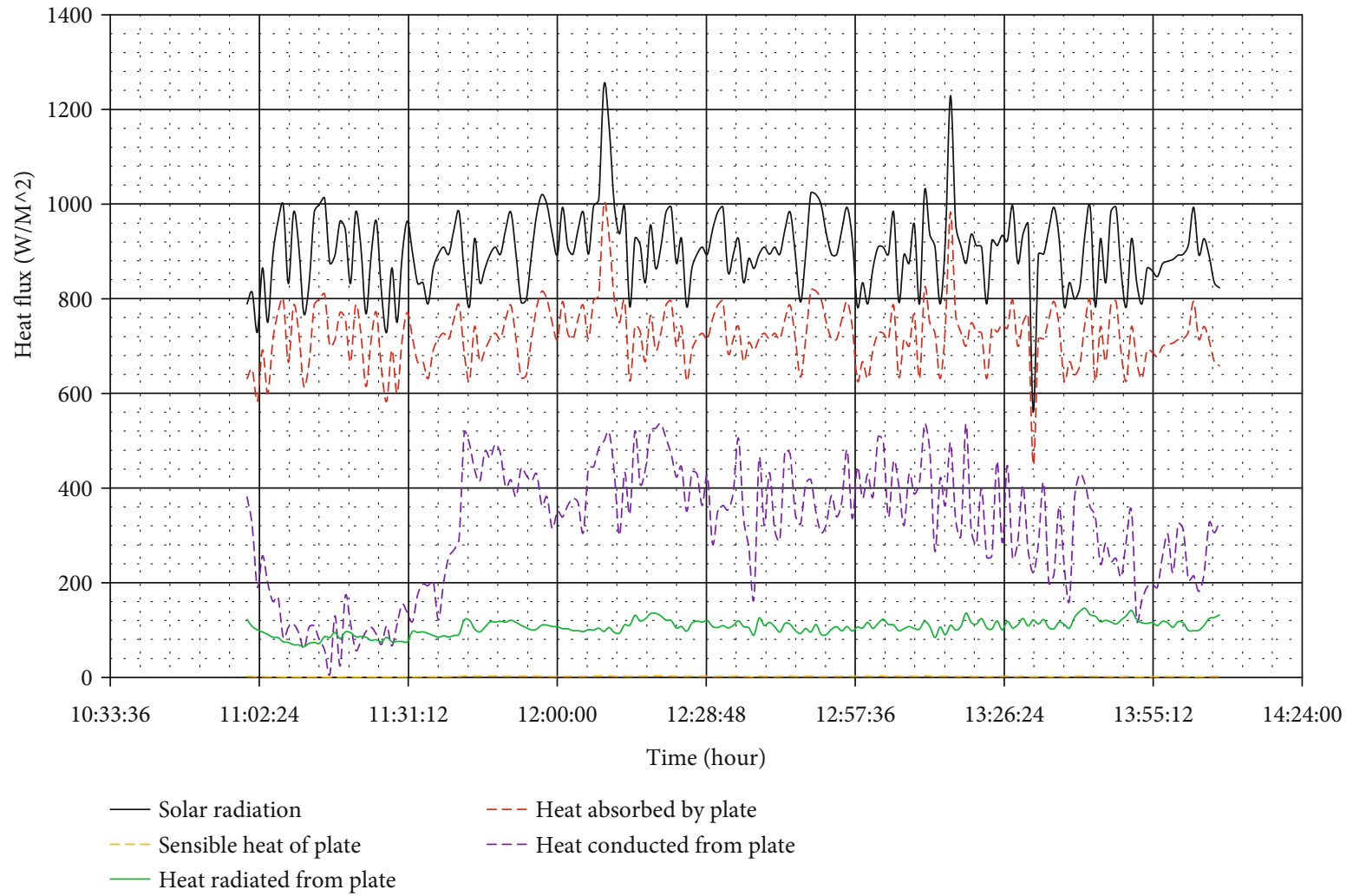

(b)

Figure 3: Plate heat flux performance (source: Authors, 2021). 


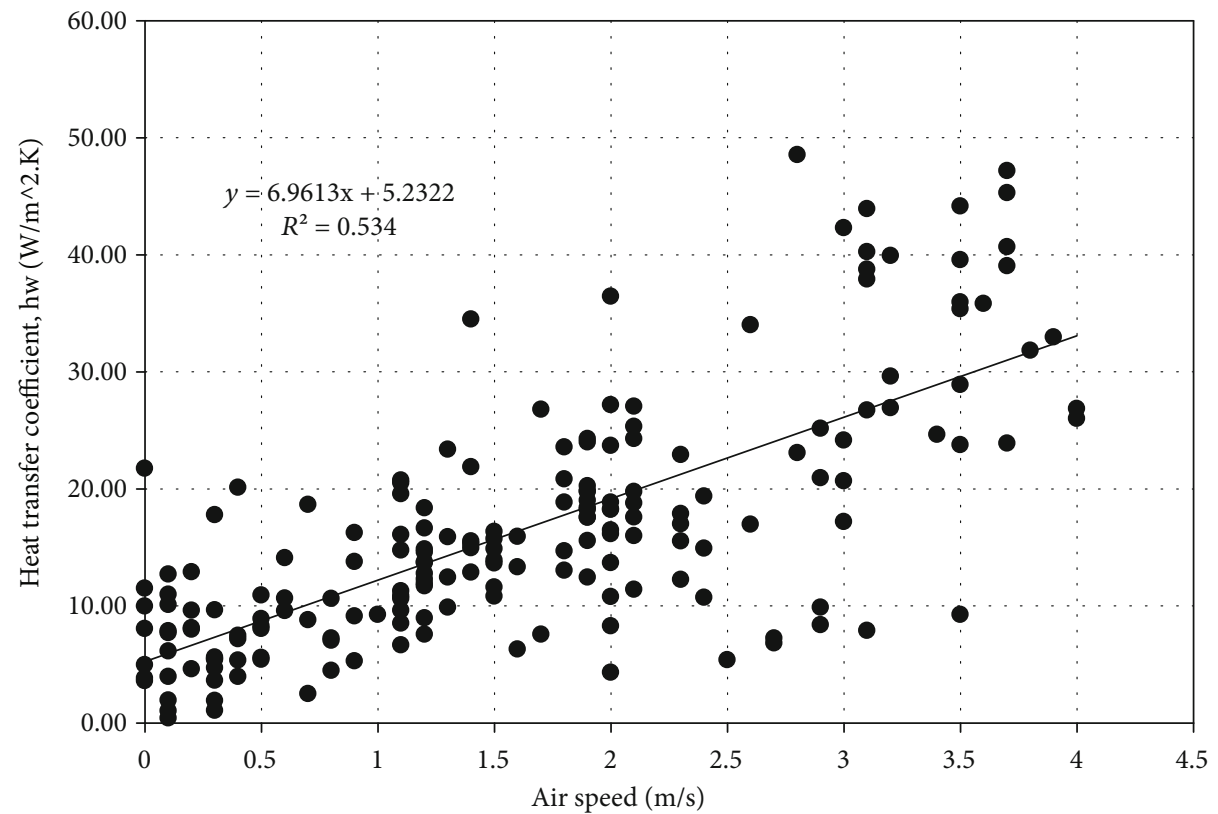

(a)

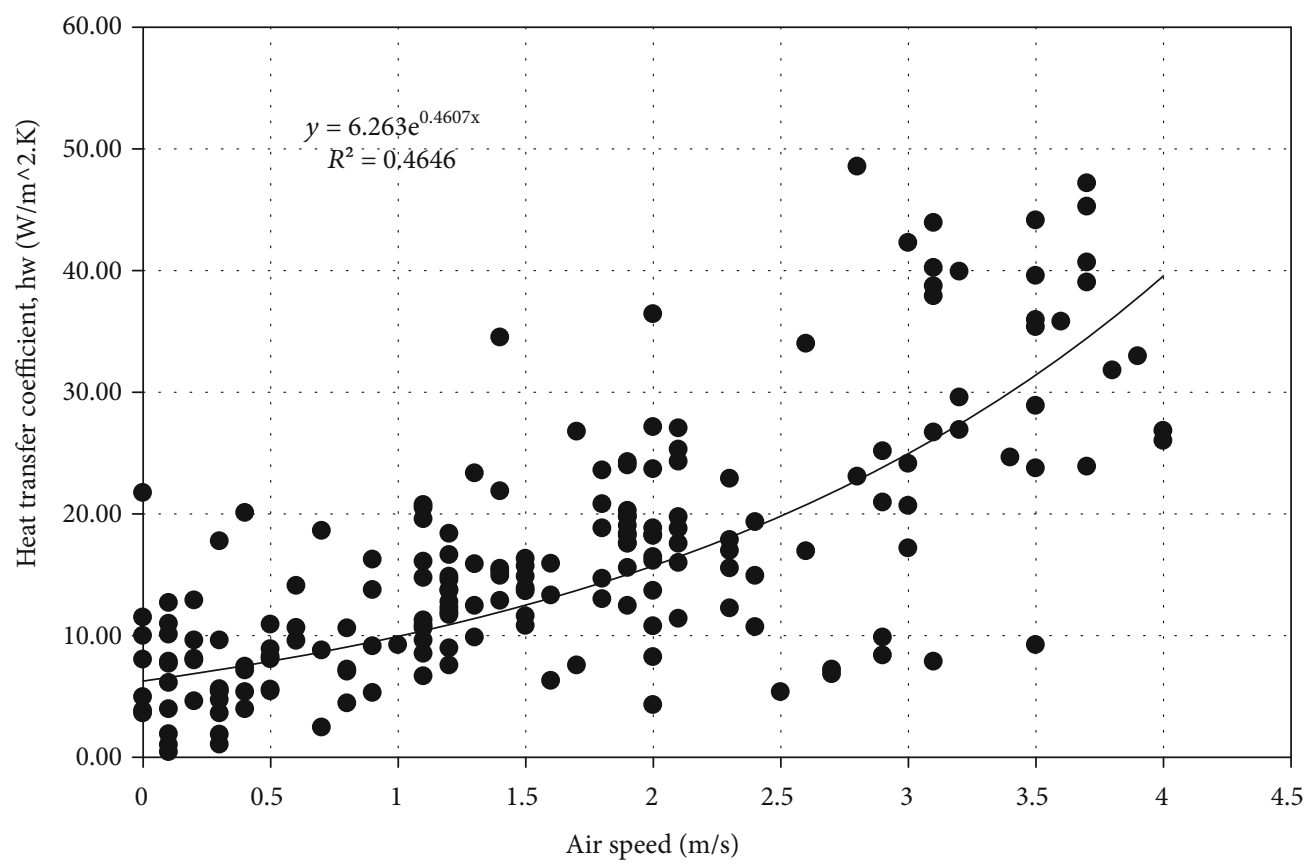

(b)

Figure 4: Regression plots: (a) linear regression of heat transfer coefficient values for various air speeds and (b) exponential regression of heat transfer coefficient values for various air speeds (source: Authors, 2021).

not really have an effect on the results. A plot of heat transfer coefficients against air speed is shown in Figure 4. This figure depicts linear (Figure 4(a)) and exponential regression (Figure 4(b)) plots which were used to draw curves of the best fit. For both cases, the regression $R$ square values are 0.5344 and 0.4646 for linear and exponential regressions, respectively. The small values show the difficulties involved in predicting the heat transfer coefficient of heat transfer on top of a mild steel plate in an unpredicted environment, but actually it confirmed the values obtained by $[3,5]$. The values of $R$ square are 0.56 and 0.78 , respectively, for the two works whose significance show the difficulties involved in producing the best curve that describes the effect of wind-induced coefficients.

The plotted points are more scattered and concentrated at low air speed which means that the area is dominated by small air speeds below $2 \mathrm{~m} / \mathrm{s}$. From the graph, it can be seen that larger wind speeds correspond to larger coefficients and there is a positive relationship between the variables, hence the positive gradient of the curve. The linear 
regression of the points yielded Equation (16) whereas the exponential regression yielded Equation (17).

$$
\begin{gathered}
h_{w}=6.9601 \mathrm{~V}+5.2311, \\
R^{2}=0.534, \\
h_{w}=6.263 e^{0.4607 V}, \\
R^{2}=0.4646 .
\end{gathered}
$$

The linear regression had a better fitting than the exponential regression; therefore, the linear regression (Equation (16)) was used.

The positive gradient of 6.96 in the linear equation shows that the margin of increment of the heat transfer coefficient is larger as compared to values such as 5.7, 3.87, and $2.8[5,11,12]$ which are mostly wind tunnel results. Values like 8.55 and 6.5 from $[4,10]$, respectively, were obtained from outdoor experimental setups. The peculiarity of the high gradients for the outdoor experimental setups makes them have higher coefficients over the indoor studios. One notable observation is the intercept of 5.23 which shows that there is always a possibility of heat transfer even at times when there are no air flows/winds.

3.3. Error Estimation from Instrumentation. When instruments are used to take measurements, there is the possibility of reading errors due to instrument limitations in measurement processes. To evaluate the extent of this error in the actual values of this study, Equations (16) through (17) to (18) were used to estimate the uncertainty introduced. An average of $14 \%$ instrumentation error was recorded for the measurements taken during this experiment. An error of $+14 \%$ is recommended for experiments whose processes are mostly automated. From the errors, it happens that the maximum error of uncertainty was recorded from the amount of heat stored in the plate, and this can be attributed to the difficulties in the measurement of the plate temperature as it loses heat to the surroundings under unpredictable conditions.

3.4. Comparison of the Present Work with Previous Works. The authors whose works were reviewed by this study all used linear regressions for their experimental analysis that is why the researchers of this study were motivated to choose the regression method for this study. This decision informed the authors of this paper to compare the difference between the empirical equations obtained by this present work with those obtained by previous works.

Complications occurred as a result of the different experimental setups (indoor and outdoor setups as adopted by [4, $5,10-12])$. Some of the experiments were held in wind tunnels kept in studios while others were done outdoors. One other factor which introduced some complications and for that matter necessitated the comparison of this present work to previous ones is the size of the plate. This particular comparison was done by normalising previous works with a relation provided by [9]. The relation is given in Equation (18) which satisfies the present model and the model presented by [9].

$$
\frac{\left(h_{w}\right)_{\mathrm{b}}}{\left(h_{w}\right)_{\mathrm{s}}}=\left(\frac{L_{\mathrm{b}}}{L_{\mathrm{s}}}\right)^{-0.2}
$$

where $L_{\mathrm{b}}$ and $L_{\mathrm{s}}$ are the characteristic length of the mild steel plate, big and small, respectively.

For the sake of analysing the various curves of the models displayed in Figure 5 (involving present and previous models), the average wind speed obtained by this research $(1.6 \mathrm{~m} / \mathrm{s})$ was used as the reference speed for comparison of the various models. The models compared to this study are those developed by [3-5, 10-12].

The presentation of the coefficients in ascending order is as follows: [4, 5, 9-12], present work, and [3].

The order shows that wind tunnel models have lower coefficient values while the outdoor setup models have larger values.

The bottom curve [12] shows a great disparity in value as compared to the rest. This phenomenon can be attributed to the fact that disturbances from the surroundings were absent in the experiment (wind tunnel). In indoor studio setups, the experimental variables are completely held under quasiequilibrium conditions throughout the experiment especially in the case of convective air. In the case of outdoor experimental setups, disturbances are felt and are unfortunate and unpredictable. For example, trees around redirect or shield the wind at the same time. This unpredictable wind surges create whirls around the plates and consequently increase the coefficient values and the temperature gradient thus leading to greater heat transfer from the plate. It can then be deduced from the values that lower disturbances create small coefficients while bigger disturbances create larger coefficients.

Another notable observation is that analytical equations and wind tunnel setups are unable to model all the environmental details including unsteady outside air flow conditions, difference in levels of turbulence, and the magnitudes and dynamics of air flow (wind). Normally, air flow in wind tunnels and analytical experiments are modelled under steady conditions while outdoor experiments are modelled under unsteady and unidirectional conditions. The unsteady nature of wind creates an unsteady boundary layer over outdoor experiments leading to the large difference in values between the two regimes (outdoor and indoor experiments).

The large differences in values recorded can also be accounted for by the flow development around the borders of the mild steel plate. The regime of flow development in unsteady and turbulent outdoor environment is nonexistent while that of the indoor experimental environment is partially/fully developed. The flow profile of outdoor experimental setups for heat transfer is usually undeveloped because the $R$ square values for outdoor heat transfer coefficients are most often small.

The change in the trend of the values of air speed for the indoor studio as depicted by [3] is higher than that of the outdoor values obtained by the same study (which is usually 


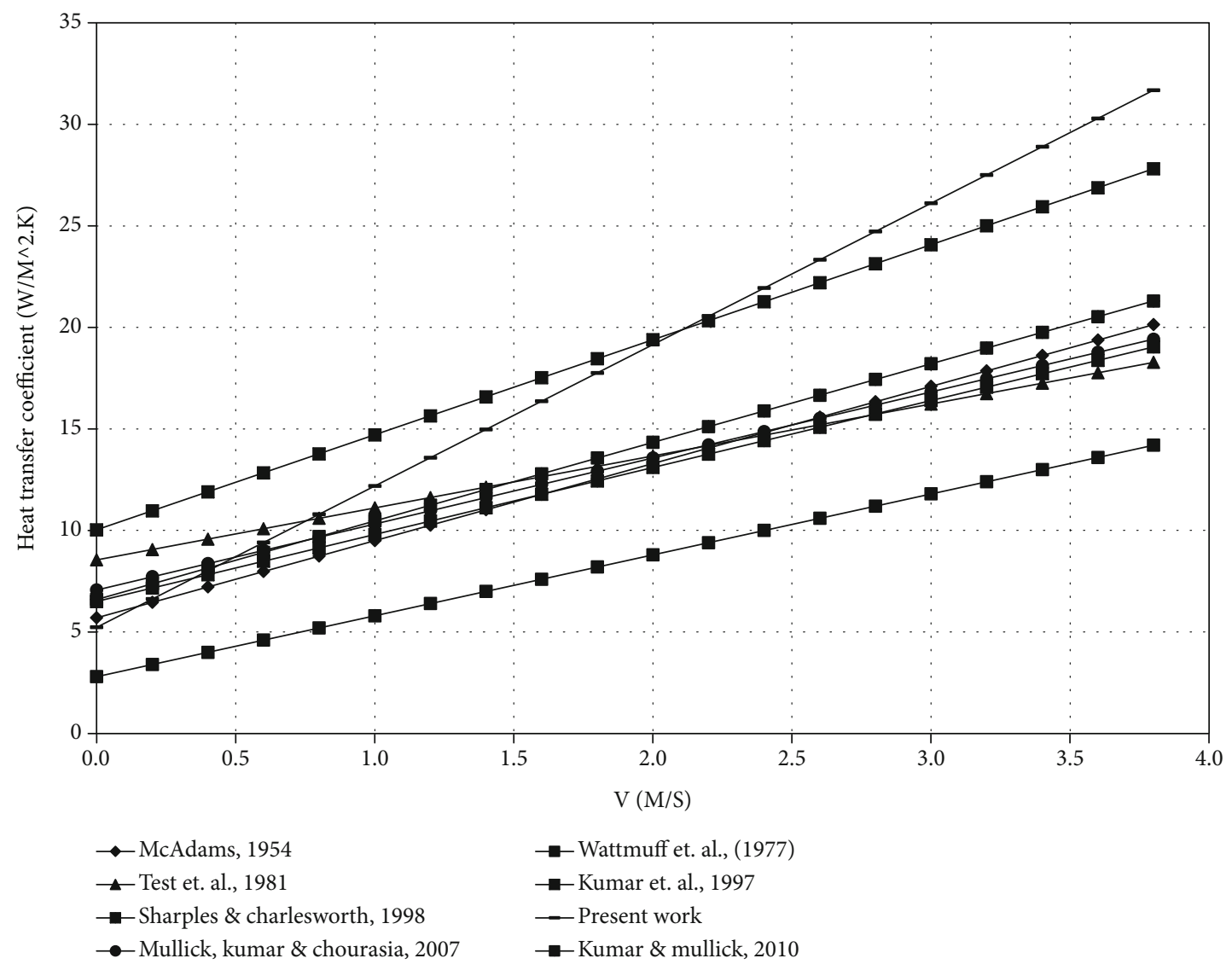

FIGURE 5: Comparison of previous models with the present model (source: Authors, 2021).

not the case) as well as this study. These values are as a result of the larger industrial fan used for indoor experiments and the scale of the experiment. Large fans create large swirls around the plate which affect the development of the boundary layer and the flow profile, hence the large heat transfer coefficient values obtained by [3].

It can therefore be concluded that heat transfer coefficients for indoor experiments should not be used for outdoor experiments without adequate justification.

\section{Conclusion}

Solar thermal collectors are special heat exchangers that absorb and transfer heat energy to other bodies. Bodies illuminated by radiation absorb and transfer part of their absorbed radiation through convection, conduction, and radiation. Systems exposed to outdoor environmental conditions undergo heat transfer or thermal exchange as a result of windinduced convection. This heat exchange between the thermal system and its environments leads to losses that have direct influence on the performance or efficiency of the system. The performance of thermal systems is normally represented by its heat loss coefficient to simplify and combine the effect of both radiation and convection modes of heat transfer.

One complicated phenomenon of heat transfer is the fact that heat loss by combination of radiation and convection is environmentally dependent. An empirical model was created outdoor to establish a relation between $h_{w}$ and $V$. The experimental parameters were measured at a time interval of 1 second for five months and averaged every 10 minutes from 11:00 A.M. to 2:00 P.M. in Sunyani, the regional capital of the Bono Region of Ghana, when the daily solar radiation was steady and stable. The heat transfer coefficient was estimated, plotted against wind speeds, and compared with previous works. It was found out that the values of heat transfer coefficients for outdoor experimental environments are higher than the values obtained by other researchers who used indoor studios, and this is due to conditions peculiar to the surroundings of the outdoor experimental setups. The conditions range from unsteady flow regimes and absence of flow profiles to unidirectional flows. A linear regression equation was used for the comparison because it satisfies the following two conditions: it is the most widely used model and it produces the highest $R$ square value. From the scatter diagram (Figure 4), it is also observed that most of the points were scattered around low speeds with few around medium speeds of 3 to $4 \mathrm{~m} / \mathrm{s}$. It is established by this study that a seemingly similar equation was used by previous works to estimate the heat transfer coefficient in outdoor conditions even though outdoor heat transfer coefficients are site-specific. For this reason, this study is proposing the use of different appropriate equations for determining heat transfer coefficients for different locations as the performance of thermal systems depends on local conditions such as solar irradiation, rainfall, and localized wind-induced convection. 


\section{Nomenclature}

$h_{w}$ : Convective heat transfer coefficient $\left(\mathrm{W} / \mathrm{m}^{2} \cdot \mathrm{K}\right)$

$V: \quad$ Air speed $(\mathrm{m} / \mathrm{s})$

L: $\quad$ Characteristic length $(\mathrm{m})$

T: $\quad$ Temperature $\left({ }^{\circ} \mathrm{C}\right)$

I: $\quad$ Radiation intensity $\left(\mathrm{W} / \mathrm{m}^{2}\right)$

m: Mass $(\mathrm{kg})$

c: $\quad$ Specific heat capacity $(\mathrm{J} / \mathrm{kg} \cdot \mathrm{K})$

$d t$ : Time interval (s)

$\dot{Q}^{\prime \prime}$ : Rate of heat flux $\left(\mathrm{W} / \mathrm{m}^{2}\right)$

$d x$ : Length $(\mathrm{m})$

$k$ : Conduction coefficient $(\mathrm{W} / \mathrm{m} \cdot \mathrm{K})$

$w$ : Error.

\section{Greek Letters}

$\alpha$ : Absorptivity

$\varepsilon$ : Emissivity

$\sigma$ : Stefan-Boltzmann constant $\left(\mathrm{W} / \mathrm{m}^{2} \cdot \mathrm{K}\right)$

$\rho:$ Density $\left(\mathrm{kg} / \mathrm{m}^{3}\right)$.

\section{Subscripts}

b: $\quad$ Big

s: $\quad$ Small

asb: Asbestos

i: Initial

f: $\quad$ Final

p: $\quad$ Plate

condlos: Heat loss by conduction

radlos: Heat loss by radiation

abplate: Absorber plate

convlos: Heat loss by convection

in: Inlet

sky: $\quad$ Sky

amb: Ambient

thick: Thickness of solid

1: $\quad$ Initial position for temperature on the plate

2: $\quad$ Final position for temperature on the plate.

\section{Data Availability}

The data used to support the findings of this study are available from the corresponding author upon request.

\section{Conflicts of Interest}

The authors declare that we have no conflict of interest. We therefore declare that our results are the true reflections of the outcomes as we were not forced with any conflict of interest.

\section{Acknowledgments}

We wish to express our profound gratitude to all the 2019 final year engineering students, both undergraduate and postgraduate students, of the University of Energy and Natural Resources, Sunyani, Ghana, who helped in the construction of the electronic device used by this study for data collection. Special thanks go to Mr. Eric Anokye Gyimah, a former student of our university, who did his voluntary service in the Mechanical and Manufacturing Engineering Department of the university.

\section{References}

[1] R. D. Clear, L. Gartland, and F. C. Winkelmann, "An empirical correlation for the outside convective air-film coefficient for horizontal roofs," Energy and Buildings, vol. 35, no. 8, pp. 797-811, 2003.

[2] P. Karava, C. M. Jubayer, and E. Savory, "Numerical modelling of forced convective heat transfer from the inclined windward roof of an isolated low-rise building with application to photovoltaic/thermal systems," Applied Thermal Engineering, vol. 31, no. 11-12, pp. 1950-1963, 2011.

[3] S. Kumar, V. B. Sharma, T. C. Kandpal, and S. C. Mullick, "Wind induced heat losses from outer cover of solar collectors," Renewable Energy, vol. 10, no. 4, pp. 613-616, 1997.

[4] F. L. Test, R. C. Lessmann, and A. Johary, "Heat transfer during wind flow over rectangular bodies in the natural environment," Transactions of the ASME Journal of Heat Transfer, vol. 103, no. 2, pp. 262-267, 1981.

[5] S. Kumar and S. C. Mullick, "Wind heat transfer coefficient in solar collectors in outdoor conditions," Solar Energy, vol. 84, no. 6, pp. 956-963, 2010.

[6] J. L. A. Francey and J. Paraioannou, "Wind-related heat losses of a flat-plate collector," Solar Energy, vol. 35, no. 1, pp. 15-19, 1985.

[7] S. Y. Wu, H. Zhang, L. Xiao, and Y. Qiu, "Experimental investigation on convection heat transfer characteristics of flat plate under environmental wind condition," International Journal of Green Energy, vol. 14, no. 3, pp. 317-329, 2017.

[8] R. J. Kind, D. H. Gladstone, and A. D. Moizer, "Convective heat losses from flat-plate solar collectors in turbulent winds," Journal of Solar energy engineering, vol. 105, no. 1, pp. 80-85, 1983.

[9] S. C. Mullick, S. Kumar, and B. K. Chourasia, "Wind induced heat transfer coefficient from flat horizontal surfaces exposed to solar radiation," Energy Sustainability, vol. 47977, pp. 1131-1137, 2007.

[10] S. Sharples and P. S. Charlesworth, "Full-scale measurements of wind-induced convective heat transfer from a roofmounted flat plate solar collector," Solar Energy, vol. 62, no. 2, pp. 69-77, 1998.

[11] W. H. McAdams, Heat Transmission, Heat Transmission, Tokyo, Japan, Third ed edition, 1954.

[12] J. H. Wattmuff, W. W. S. Charters, and D. Proctor, "Solar and wind induced external coefficients for solar collectors," Internationale Revue d'Heliotechnique, vol. 2, p. 56, 1977.

[13] E. Sartori, "Convection coefficient equations for forced air flow over flat surfaces," Solar Energy, vol. 80, no. 9, pp. 1063-1071, 2006.

[14] E. M. Sparrow, J. W. Ramsey, and E. A. Mass, "Effect of finite width on heat transfer and fluid flow about an inclined rectangular plate," Journal of Heat Transfer, vol. 101, no. 2, pp. 199204, 1979. 